\title{
Efficacy of Autogenous Bone Marrow Aspirate as a Fusion-promoting Adjunct to Anterior Cervical Discectomy and Fusion: A Single Center Retrospective Cohort Study
}

\author{
Sean M. Barber ${ }^{1}$, Majdi Radaideh ${ }^{2}$, Rob Parrish ${ }^{1}$ \\ 1. Department of Neurosurgery, Houston Methodist Neurological Institute, Houston, USA 2. Neuroradiology, Houston \\ Methodist Neurological Institute, Houston, USA
}

Corresponding author: Sean M. Barber, smbarber@houstonmethodist.org

\section{Abstract \\ Background}

Autogenous iliac crest bone marrow aspirate (BMA) has been shown to be a safe osteobiological adjunct to anterior cervical discectomy and fusion (ACDF), but little evidence exists to support its superiority to traditional methods. The object of this study was to retrospectively evaluate two cohorts of patients undergoing ACDF - with or without the use of BMA - in an effort to better characterize the clinical and radiographic outcomes associated with the use of BMA in ACDF.

\section{Methods}

The charts of all patients undergoing ACDF with a collagen-hydroxyapatite (CHA) sponge, local vertebral autograft and a polyetheretherketone (PEEK) interbody graft with or without BMA by a single staff neurosurgeon between 2011 and 2016 were retrospectively reviewed. Post-operative dynamic plain films and CT scans for each patient were reviewed and each instrumented level was independently evaluated for fusion over time.

\section{Results}

A total of 203 cervical levels were instrumented in 92 patients (with BMA, 52 patients, 122 levels; without BMA, 40 patients, 81 levels). The mean radiographic follow-up period was $21.4 \pm 18.4$ months, over which time 154 of 203 (75.6\%) instrumented cervical levels were found to have fused (BMA group, 93/122 segments fused [76.2\%]; non-BMA group, 61/81 segments fused [75.3\%], p = 1). Kaplan-Meier survival analysis demonstrated a higher probability of fusion at any given time point for the BMA group when compared with the non-BMA group ( $\mathrm{p}<0.001$, log-rank test).

Received 01/02/2018

Review began 03/05/2018 Review ended 04/01/2018 Published 05/16/2018

(c) Copyright 2018

Barber et al. This is an open access article distributed under the terms of the Creative Commons Attribution License CC-BY 3.0., which permits unrestricted use, distribution, and reproduction in any medium, provided the original author and source are credited.

\section{Conclusions}

BMA is a readily accessible, low-cost adjunct to ACDF that enhances the fusion rates seen with a CHA/PEEK allograft combination.

Categories: Neurosurgery, Orthopedics

Keywords: spinal fusion, bone marrow, autograft

\section{Introduction}

Although anterior cervical discectomy and fusion (ACDF) is typically successful at producing osseous fusion of instrumented levels, pseudarthroses - when present - may necessitate re-operation and/or serve as a source of ongoing pain and neurologic symptoms. Efforts to reduce the pseudarthrosis rate after ACDF have led to procedural refinements such as anterior plating systems [1] and the use of a wide variety of grafting materials and osteobiologic adjuncts [2,3]. While autogenous tricortical iliac crest bone graft (ICBG) has been used for decades as an effective graft material for ACDF and is often considered the "gold standard" [2], the morbidity associated with ICBG harvesting has led many surgeons to consider alternative grafting materials [4]. Because the osteogenic potential of cancellous bone has been shown to originate from the osteoprogenitor cells present within bone marrow, many have advocated for the use of bone marrow aspirate as an adjunct to fusion procedures within the spine and elsewhere [5-9]. Although the use of bone marrow aspirate (BMA) as an adjunct to ACDF has been shown to be relatively safe and outcomes have been shown to be relatively favorable $[8,10]$, definitive evidence of efficacy and/or superiority to other methods is lacking [11].

The authors performed a retrospective review of patients undergoing ACDF - with or without the use of BMA - by a single neurosurgeon at our institution over a period of five years in order to better characterize 


\section{Materials And Methods}

\section{Study design}

This single-center, retrospective cohort study was carried out with the approval of the Institutional Review Board of our hospital. Charts for all patients having undergone ACDF by the senior author at our institution between April 2011 and May 2016 were reviewed. The senior author did not use BMA as an adjunct to ACDF initially during the study period, but began to do so semi-exclusively starting in 2013.

Patient identification took place through review of institutional operative records. All patients having undergone ACDF by the senior author between April 2011 and May 2016 were considered potentially eligible. Exclusion criteria included: (1) history of prior ACDF at a given segment, (2) corpectomy at a given segment, (3) absence of at least six months of radiographic (i.e., dynamic cervical spine plain films and/or cervical spine computed tomography (CT) scans) and clinical follow-up post-operatively, (4) lack of access to preoperative films, or (5) simultaneous posterior decompression and/or instrumentation. Clinical data collected included operative complications, post-operative clinical status, and need for re-operation. Radiographic assessment of fusion was based on cervical flexion-extension x-rays and/or CT scans.

\section{Surgical technique}

ACDF was performed in each case using standard techniques. In patients undergoing bone marrow aspiration, however, the ipsilateral anterior iliac crest is also prepared and draped. After anterior cervical discectomy is complete, a small incision is then made above the anterior superior iliac spine. An 11G bone marrow needle and trocar are inserted into this incision and carried down to the bone. The needle and trocar are then advanced $2 \mathrm{~cm}$ in line with the slope of the anterior iliac crest. The trocar is then removed and a 2 $\mathrm{mL}$ of bone marrow is aspirated. In cases where additional BMA is required (e.g., multi-level fusions), the needle is then advanced slightly before withdrawing additional BMA. The BMA is then passed through a collagen-hydroxyapatite (CHA) sponge within a vacuum chamber without centrifugation or other alterations. The treated sponge is then placed within the pre-selected polyetheretherketone (PEEK) graft along with local vertebral autograft prior to graft implantation. Additional sponge material is placed laterally near the uncovertebral joints at the instrumented level. The procedure for patients undergoing ACDF without the use of BMA was identical, with the exception that BMA was not harvested, and the CHA sponge was instead soaked with normal saline prior to implantation.

\section{Criteria for determination of radiographic fusion}

Clinical and radiographic follow-up was maintained for at least six months post-operatively in all patients. Radiographic fusion was determined after review of the post-operative films with a blinded neuroradiologist. Each instrumented segment was evaluated independently. In order to be considered radiographically fused, each of the following criteria had to be satisfied at the instrumented segment: (1) less than $1 \mathrm{~mm}$ interspinous movement on flexion/extension films, (2) less than 2 degrees of angular movement of instrumented endplates on flexion/extension films, (3) absence of interfacet movement on flexion/extension films, and (4) absence of radiolucencies around the graft or other hardware. If CT was available, evidence of bridging trabecular bone at the instrumented level was required for the segment to be considered fused. If any of these criteria were not satisfied, the segment was deemed unfused.

\section{Statistical methods}

Frequency distributions and summary statistics were calculated for all clinical and radiographic variables. Fisher's exact test was used to compare distributions for categorical variables and t-tests were used to investigate differences in the distributions of continuous variables between subsets of patients classified by dichotomous data. Pearson correlation coefficients were calculated to evaluate associations between fusion rates and dichotomous patient data (e.g., age, gender, smoking status). Kaplan-Meier survival analysis was used to compare the probability of fusion over time for segments in each of the two study groups. A p-value of 0.05 or less was considered significant.

\section{Results}

\section{Participants}

Ninety-two patients and 203 operative levels were included in this retrospective review. Fifty-two of the included patients (122 instrumented levels) underwent ACDF with the use of autogenous iliac crest BMA, while the other 40 patients ( 81 instrumented levels) underwent ACDF without BMA. Fifty-six of the study patients were female (60.9\%) and 36 patients were male (39.1\%). The mean age for the entire cohort was $53 \pm$ 10 years. Active smoking status was confirmed by chart review in 14 patients $(15.2 \%)$. Study patients presented with some combination of neck pain $(\mathrm{N}=63,68.5 \%)$, radiculopathy $(\mathrm{N}=53,57.8 \%)$ and/or myelopathy $(\mathrm{N}=34,37 \%)$. Patient demographics and pre-operative symptoms are detailed in Table 1 . 


\section{Cureus}

\begin{tabular}{|c|c|c|c|c|}
\hline & Total & BMA & Non-BMA & $\mathbf{p}$ \\
\hline N & 92 & 52 & 40 & \\
\hline Segments Instrumented & 203 & 122 & 81 & \\
\hline Segments Instrumented per Patient & 2.21 & 2.35 & 2.03 & 0.062 \\
\hline Age & 53 & 54 & 53 & 0.66 \\
\hline Male & $39(39.1 \%)$ & $18(34.6 \%)$ & $18(45 \%)$ & $0.1 / 1$ \\
\hline Female & $56(60.9 \%)$ & $34(65.3 \%)$ & $22(55 \%)$ & 0.171 \\
\hline Current Smoker & $14(15.2 \%)$ & $5(9.6 \%)$ & $9(22.5 \%)$ & 0.557 \\
\hline \multicolumn{5}{|l|}{ Pre-operative Symptoms } \\
\hline Neck Pain & $63 / 92(68.5 \%)$ & $39 / 52(75 \%)$ & $24 / 40$ (60\%) & 0.174 \\
\hline Radiculopathy & $53 / 92(5 \% .6 \%)$ & $29 / 52(55.8 \%)$ & $24 / 40(60 \%)$ & 0.832 \\
\hline Myelopathy & $34 / 92(37 \%)$ & 19/52 (36.5\%) & $15 / 40(37.5 \%)$ & 1 \\
\hline \multicolumn{5}{|l|}{ Comorbidities } \\
\hline Hypertension & 35/92 (38\%) & 20/52 (38.5\%) & $15 / 40(37.4 \%)$ & 1 \\
\hline Hyperlipidemia & 18/92 (19.6\%) & $5 / 52(9.6 \%)$ & $13 / 40(32.5 \%)$ & 0.008 \\
\hline Hypothyroidism & $15 / 92(16.3 \%)$ & $9 / 52(17.3 \%)$ & $6 / 40(15 \%)$ & 1 \\
\hline Diabetes Mellitus & 9/92 (9.8\%) & 4/52 (7.7\%) & $5 / 40(12.5 \%)$ & 0.495 \\
\hline Coronary Artery Disease & 8/92 (8.7\%) & $3 / 52(5.8 \%)$ & $5 / 40(12.5 \%)$ & 0.287 \\
\hline Rheumatoid Arthritis & 6/92 (6.5\%) & $2 / 52(3.8 \%)$ & 4/40 (10\%) & 0.398 \\
\hline Atrial Fibrillation & $5 / 92(5.4 \%)$ & $1 / 52(1.9 \%)$ & $4 / 40(10 \%)$ & 0.163 \\
\hline
\end{tabular}

\section{TABLE 1: Demographics, presenting symptoms and comorbidities.}

Demographics, presenting symptoms and comorbidities of 92 patients undergoing ACDF with - or without - the use of autogenous BMA.

ACDF: Anterior cervical discectomy and fusion; BMA: Bone marrow aspirate; HTN: Hypertension; HLD: Hyperlipidemia; DM: Diabetes mellitus; CAD: Coronary artery disease; RA: Rheumatoid arthritis; Afib: Atrial fibrillation.

\section{Clinical outcomes}

The mean clinical follow-up length for the entire study population was $22.5 \pm 18.4$ months. $82 / 92$ (89.1\%) patients reported improvement in their pre-operative symptoms at the latest follow-up visit, while 10/92 patients reported stable symptoms (10.9\%). Minor complications occurred in 4/92 patients (4.3\%), including dysphagia (2/92 patients, $2.2 \%$ ), dysphonia (1/92 patients, $1.1 \%$ ), and Horner's syndrome (1/92 patients, 1.1\%). No patient underwent revision of their ACDF during the study period, but $8 / 92$ patients (8.7\%) underwent further decompression at the same cervical segment from a posterior approach due to persistent or worsening neurological symptoms and persistent spinal cord or nerve root compression on post-operative imaging. No patient reported prolonged pain at the BMA donor site. Several patients (9/92 patients, 9.8\%) were placed on an osteostimulator device post-operatively due to less-than-satisfactory bone growth on post-operative follow-up plain films. Post-operative symptom improvement $(\mathrm{P}=0.096)$, complication rates $(P=0.314)$, re-operation rates $(P=0.724)$ and rates of osteostimulator use $(P=0.495)$ were not statistically different between BMA and non-BMA groups, although a trend toward improved post-operative symptom improvement was seen in the BMA group. Clinical outcomes are detailed in Table 2. 


\section{Cureus}

\begin{tabular}{|c|c|c|c|c|}
\hline & Total & BMA & Non-BMA & $\mathbf{p}$ \\
\hline Mean Clinical Follow-up (Months) & $22.5 \pm 18.4$ & $13.8 \pm 8.4$ & $31.3 \pm 21.4$ & $<0.001$ \\
\hline Symptoms Improved Post-operatively & 82/92 patients $(89.1 \%)$ & 49.52 patients (94.2\%) & $33 / 40$ patients $(82.5 \%)$ & 0.096 \\
\hline Symptoms Stable Post-operatively & 10/92 patients (10.9\%) & $3 / 52$ patients $(5.8 \%)$ & 7/40 patients $(17.5 \%)$ & 0.096 \\
\hline Symptoms Worsened Post-operatively & $0 / 250$ patients $(0 \%)$ & $0 / 250$ patients $(0 \%)$ & $0 / 250$ patients $(0 \%)$ & 1 \\
\hline Minor Complications & 4/92 patients $(4.3 \%)$ & $1 / 52$ patients $(1.9 \%)$ & $3 / 40$ patients $(7.5 \%)$ & 0.314 \\
\hline Reoperation at Same Level & $8 / 92$ patients $(8.7 \%)$ & $4 / 52$ patients $(7.7 \%)$ & $4 / 40$ patients $(10 \%)$ & 0.724 \\
\hline Osteostimulator Used Post-operatively & 9/92 patients $(9.8 \%)$ & $4 / 52$ patients $(7.7 \%)$ & $5 / 40$ patients $(12.5 \%)$ & 0.495 \\
\hline
\end{tabular}

\section{TABLE 2: Clinical outcomes.}

Clinical outcomes in 92 patients undergoing ACDF with - or without - the use of autogenous BMA.

ACDF: Anterior cervical discectomy and fusion; BMA: Bone marrow aspirate.

\section{Radiographic outcomes}

The mean radiographic follow-up period for all 92 study patients was $21.4 \pm 18.4$ months. At the end of the study period, 154/203 (75.9\%) of all instrumented segments were considered fused. No significant difference was seen between the fusion rates in the BMA versus the non-BMA group $(\mathrm{P}=1$, Table 3 , Figure 1$)$. The rate of fusion in the BMA group (9.8\% of segments fused per month of follow-up), however, was significantly greater than that seen in the non-BMA group (6.1\% of segments fused per month of follow-up, $\mathrm{p}=0.003$ ). Further investigation with Kaplan-Meier survival analysis and the log-rank test revealed that the probability of fusion over the course of radiographic follow-up was significantly greater for the BMA group when compared with the non-BMA group ( $<<0.001$; Figure 2). No significant relationship was seen between patient age $(R=0.232, p=0.79)$, patient gender $(p=0.29)$, use of an osteostimulator $(p=0.85)$ or smoking status $(\mathrm{p}=0.11)$ and the rate of fusion amongst study patients. 


\section{Cureus}

\begin{tabular}{|c|c|c|c|c|}
\hline & Total & BMA & Non-BMA & $\mathbf{p}$ \\
\hline Mean Radiographic Follow-up (months) & $21.4 \pm 18.4$ & $\begin{array}{l}12.9 \pm 8.3 \text { (range, } 6- \\
41)\end{array}$ & $\begin{array}{l}32.4 \pm 21.8 \text { (range, } \\
6-66)\end{array}$ & $<0.001$ \\
\hline Segments Fused at Latest Radiographic Follow-up & $\begin{array}{l}154 / 203 \text { segments } \\
(75.9 \%)\end{array}$ & $\begin{array}{l}\text { 93/122 segments } \\
(76.2 \%)\end{array}$ & $\begin{array}{l}61 / 81 \text { segments } \\
(75.3 \%)\end{array}$ & 1 \\
\hline 6 months & $\begin{array}{l}40 / 94 \text { segments } \\
(42.6 \%)\end{array}$ & $\begin{array}{l}31 / 71 \text { segments } \\
(43.6 \%)\end{array}$ & $\begin{array}{l}\text { 9/23 segments } \\
(39.1 \%)\end{array}$ & 0.81 \\
\hline 12 months & $\begin{array}{l}103 / 157 \text { segments } \\
(65.6 \%)\end{array}$ & $\begin{array}{l}78 / 112 \text { segments } \\
(69.6 \%)\end{array}$ & $\begin{array}{l}25 / 45 \text { segments } \\
(55.6 \%)\end{array}$ & 0.098 \\
\hline 18 months & $\begin{array}{l}110 / 166 \text { segments } \\
\text { (66.3\%) }\end{array}$ & $\begin{array}{l}81 / 118 \text { segments } \\
(68.6 \%)\end{array}$ & $\begin{array}{l}29 / 48 \text { segments } \\
(60.4 \%)\end{array}$ & 0.366 \\
\hline 24 months & $\begin{array}{l}119 / 168 \text { segments } \\
\text { (70.8\%) }\end{array}$ & $\begin{array}{l}88 / 120 \text { segments } \\
(73.3 \%)\end{array}$ & $\begin{array}{l}31 / 48 \text { segments } \\
(61.6 \%)\end{array}$ & 0.266 \\
\hline 30 months & $\begin{array}{l}125 / 174 \text { segments } \\
\text { (71.8\%) }\end{array}$ & $\begin{array}{l}91 / 122 \text { segments } \\
(75.4 \%)\end{array}$ & $\begin{array}{l}38 / 54 \text { segments } \\
(70.3 \%)\end{array}$ & 0.577 \\
\hline 36 months & $\begin{array}{l}130 / 176 \text { segments } \\
\text { (73.9\%) }\end{array}$ & $\begin{array}{l}\text { 92/122 segments } \\
(75.4 \%)\end{array}$ & $\begin{array}{l}38 / 54 \text { segments } \\
(70.3 \%)\end{array}$ & 0.577 \\
\hline 42 months & $\begin{array}{l}133 / 180 \text { segments } \\
(73.9 \%)\end{array}$ & $\begin{array}{l}93 / 122 \text { segments } \\
(76.2 \%)\end{array}$ & $\begin{array}{l}40 / 58 \text { segments } \\
(70.0 \%)\end{array}$ & 0.364 \\
\hline $\begin{array}{l}\text { Segments Fused per Month of Radiographic Follow- } \\
\text { up (\%/month) }\end{array}$ & 8.2 & 9.8 & 6.1 & 0.009 \\
\hline
\end{tabular}

\section{TABLE 3: Radiographic outcomes.}

Radiographic outcomes for 92 patients undergoing ACDF with - or without - the use of autogenous BMA.

ACDF: Anterior cervical discectomy and fusion; BMA: Bone marrow aspirate.

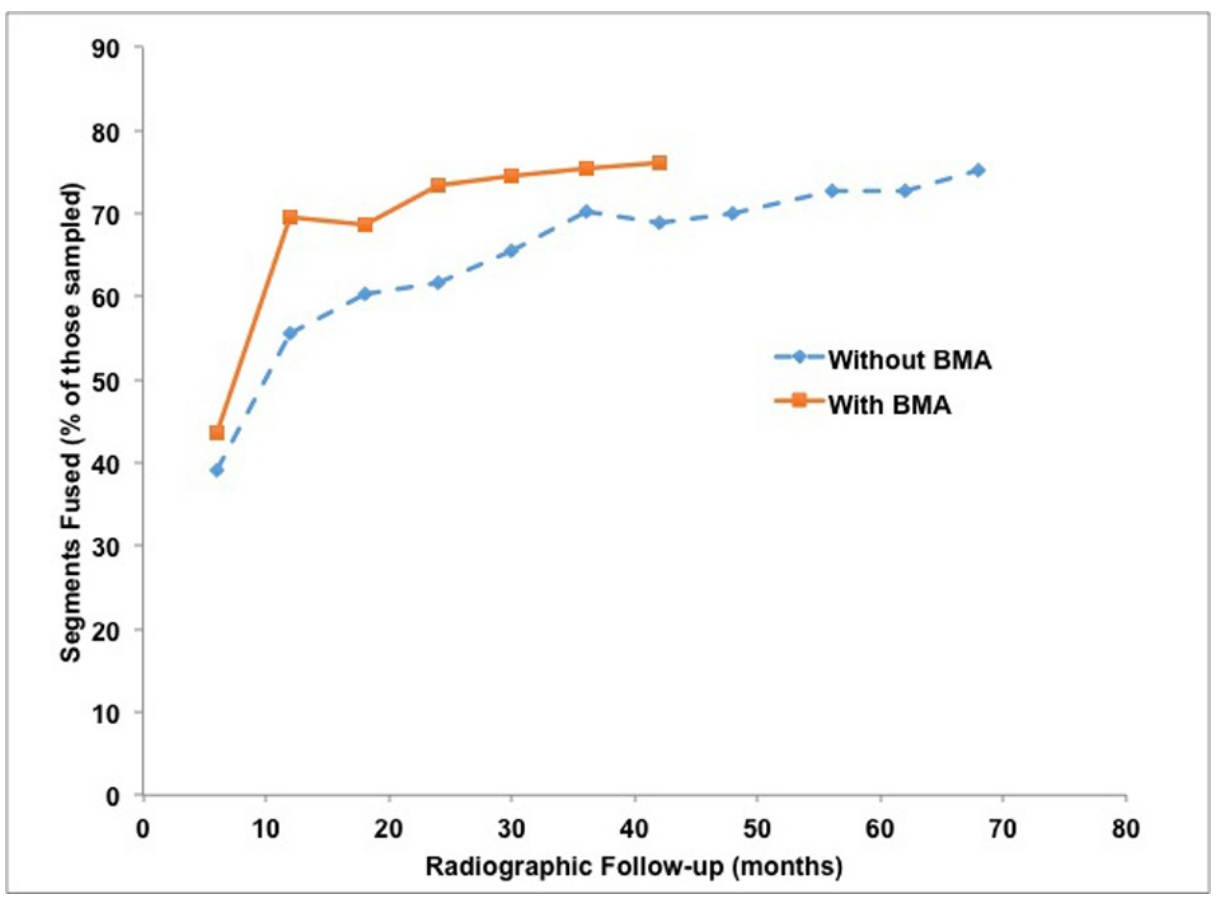

FIGURE 1: Fusion rates over time.

Line graph illustration of radiographic fusion rates after ACDF with - or without - the use of autogenous BMA adjunct in the 92 study patients. Percentages are calculated for patients with available imaging data at each 


\section{Cureus}

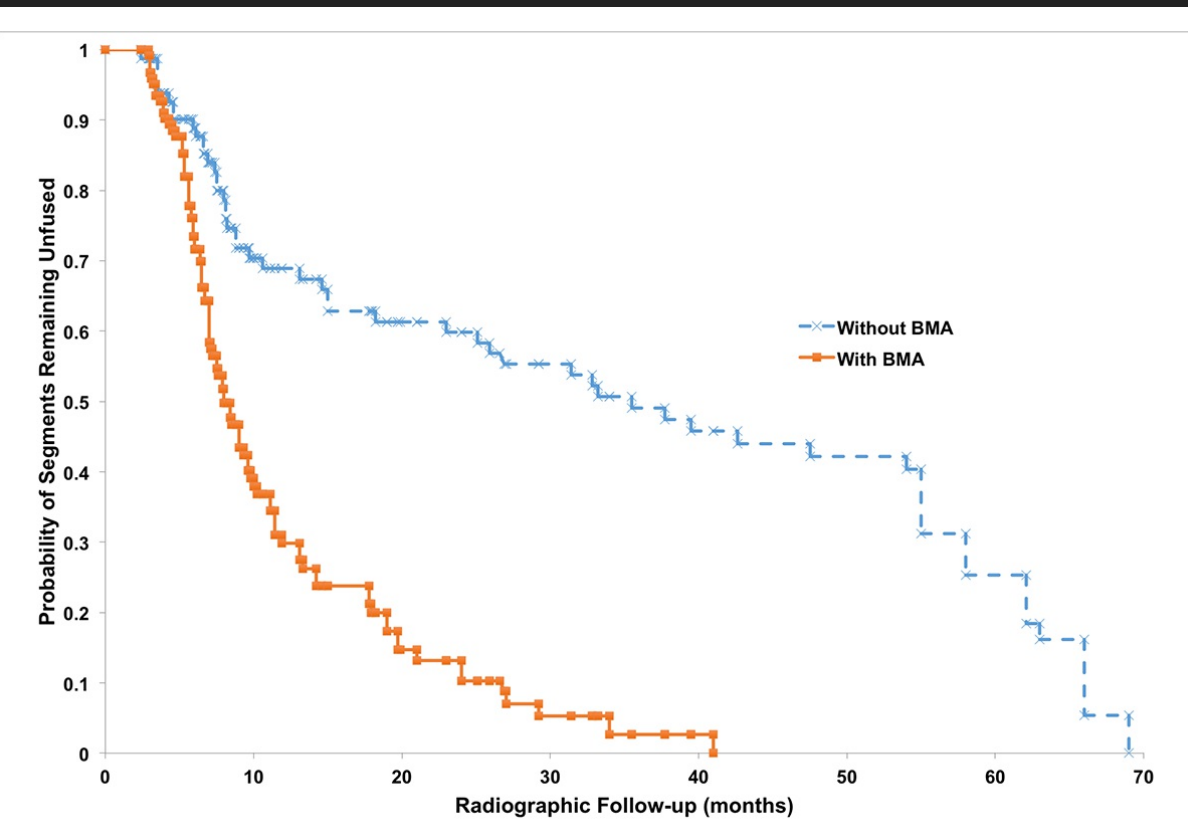

\section{FIGURE 2: Probability of fusion over time.}

Kaplan-Meier survival analysis displaying probability of fusion over time for 286 instrumented segments treated with - or without - autogenous BMA. Log-rank test revealed a statistically significant difference between the two curves $(p<0.001)$.

BMA: Bone marrow aspirate

\section{Discussion}

\section{Rationale for use of BMA in spinal fusion}

Successful arthrodesis relies upon the principles of osteogenesis, osteoconduction and osteoinduction [12]. Osteogenic potential is the capacity for a graft or other material to form new bone, a process dependent on the presence within a given site of an adequate number of viable cells with bone-forming capabilities (e.g., osteoprogenitor cells). Osteoconductiveness is the ability of a graft or other material to provide a suitable physical matrix for the influx and attachment of osteoprogenitor cells, neovascularization and bony deposition. Osteoinduction is the process whereby immature, pluripotent stem cells are induced by a variety of growth factors and other environmental cues to become mature osteoblasts, osteoclasts and osteocytes. ICBG and other autograft bone is said to possess all three of these qualities [2], but ICBG harvest leads to chronic donor site pain and even functional impairment in many patients $[4,13]$. Though PEEK possesses certain structural qualities desirable in an interbody graft (e.g., elastic modulus similar to that of bone; radiolucency allowing for post-operative visualization of bone growth) [14], being a synthetic polymer it does not itself contain osteogenetic, osteoconductive or osteoinductive properties. Instead, PEEK cages, like other synthetic cages, are typically combined with local bone and/or allograft materials (e.g., demineralized bone matrix [DBM]) possessing the qualities necessary to induce bone formation.

The capacity for bone marrow to induce ectopic bone formation was recognized as early as the 19th century [11]. Further study has suggested that this bone-forming ability is related to the presence within BMA of osteoprogenitor cells with inherent osteogenetic potential (albeit at a relatively low concentration $[1 / 100,000-500,000$ cells] $[11,15,16]$. The presence of these osteoprogenitor cells within BMA, the relative ease with which BMA may be harvested, the low cost of BMA harvest and the low patient morbidity associated with harvest makes BMA an attractive adjunct to spinal fusion procedures. Indeed, numerous animal studies have demonstrated that BMA enhances the rate of spinal fusion seen with ICBG [17] or DBM [18-19]. Likewise, the results of some animal studies suggest that autologous BMA improves the fusion rates seen with engineered, biodegradable, osteoconductive matrices (e.g., CHA sponges) [20-22] and recombinant human bone morphogenetic protein (rhBMP) [23]. 


\section{Literature evidence for BMA efficacy in spinal fusion}

Very few clinical studies have evaluated the comparative efficacy of autologous BMA versus other graft materials in human spinal fusion [11]. Price et al. compared a BMA-DBM composite to ICBG and freeze-dried corticocancellous autografts in a retrospective series of 73 patients undergoing fusion for adolescent idiopathic scoliosis and found no significant difference between the pseudarthrosis rates of ICBG and BMADBM [24]. Korovessis et al. prospectively compared ICBG to hydroxyapatite + local bone + BMA in 57 patients undergoing decompression and posterolateral fusion for degenerative lumbar stenosis and found no difference in the fusion rates or clinical outcomes one-year postoperatively [25]. With respect to ACDF, specifically, no comparative studies are available. Papavero et al. prospectively evaluated 78 patients undergoing ACDF with a titanium cage filled with a hydroxyapatite/BMA mixture and favorable clinical and radiographic outcomes were seen, but no control (i.e., non-BMA) group was studied for comparison [10]. Similarly, Khoueir et al. retrospectively studied 66 patients who underwent ACDF with a combination of a fibular strut allograft, a CAH sponge and autogenous BMA [8]. Although favorable clinical and radiographic outcomes were demonstrated, no control group was available for comparison. The present series constitutes the first controlled study to evaluate the efficacy of a BMA-hydroxyapatite-PEEK-local bone combination versus hydroxyapatite-PEEK-local bone alone in ACDF.

The results of this study demonstrate that autogenous BMA, when combined with a CAH sponge, PEEK interbody graft and local autograft in the setting of ACDF, results in faster radiographic fusion than CAH/PEEK/local autograft alone. Although a trend was seen towards improved clinical outcomes and 12month fusion rates in the BMA group, these results did not reach statistical significance.

\section{Limitations}

This study is limited primarily by its retrospective nature, which predisposes the results to errors of bias and confounding. In retrospective cohort studies comparing treatment results, selection bias is of particular concern. In the present study, the decision to treat with - or without - BMA was incidental and related only to the time during the study period at which the patient underwent ACDF, as the senior author did not use BMA as an adjunct to ACDF initially within the study period, but began to do so semi-exclusively in 2013 as a result of a growing body of evidence (described above) supporting the efficacy of BMA as an adjunct to ACDF. Similarly, the significant discrepancy between the length of radiographic follow-up between BMA and non-BMA groups was a factor of the same change in practice patterns. Patients undergoing ACDF without BMA were treated earlier in the study period than those undergoing ACDF with BMA.

An additional limitation inherent within studies of spinal fusion is the indirect assessment of spinal fusion through radiographic means, which has been shown to be unreliable at times $[25,26]$. The "gold standard" determination of spinal fusion occurs through operative exploration, but - with the exception of revision cases - this approach is not practical in a clinical setting. Both CT and static radiographs have been shown to overestimate fusion rates in some studies $[26,27]$. Dynamic radiographs are limited by extent of patient effort/motion between flexion and extension, measurement reliability, controversy regarding the degree of allowable motion and the problematic endeavor of using two-dimensional films to evaluate a threedimensional process (i.e., fusion) [27]. In an effort to provide greater specificity regarding fusion rates in this study (perhaps at the expense of sensitivity), we utilized dynamic films and/or CT imaging alone in our determination of fusion rates, and the criteria employed were a relatively strict combination of those employed throughout the literature [28-30].

Additional investigation is needed to determine to what degree altering the concentration or viability of osteoprogenitor cells present within BMA (e.g., through centrifugation or culturing) influences radiographic and/or clinical outcomes of spinal fusion, as some authors have suggested [6,19].

\section{Conclusions}

BMA is a readily accessible, low-cost adjunct to ACDF that enhances the fusion rates seen with a $\mathrm{CAH} / \mathrm{PEEK} /$ local autograft combination. Further investigation is warranted regarding the value of BMA postprocessing and the combination of BMA with other grafting materials in ACDF.

\section{Additional Information \\ Disclosures}

Human subjects: Consent was obtained by all participants in this study. Methodist Online Research Technology Initiative (MORTI) issued approval Pro 00015558. NOTIFICATION OF INITIAL APPROVAL TO BEGIN RESEARCH (EXPEDITED) To: Dr. Rob Parrish From: Dr. Susan Miller Chair, HMRI IRB1 Date: October 21, 2016 Study ID: Pro00015558 Title: The Effect of Bone Marrow Aspirate on Fusion Rates in Anterior Cervical Discectomy and Fusion The Institutional Review Board reviewed your Request for Expedited Review and the above named project is determined to qualify for Expedited status according to 45 CFR 46.110. The study is approved from 10/18/2016 through 10/17/2019. CATEGORY \#5: Research involving materials (data, documents, records, or specimens) that have been collected, or will be collected solely for nonresearch purposes (such as medical treatment or diagnosis). (NOTE: Some research in this category may be exempt 
from the HHS regulations for the protection of human subjects. 45 CFR 46.110 (4). This listing refers only to research that is not exempt.) Protocol(0.01) Data collection sheet 45 CFR 46.116 (d): Waiver of Informed Consent for Minimal Risk Research Waiver of Authorization to Use and Disclose Protected Health Information The IRB has determined all the specified criteria for a waiver or an alteration were met in accordance with 45 CRF 164.512(i). Under this approval, the following data elements may be used/accessed in connection with this study: • HIPAA waiver to review charts for Hospital or Medical Records and Medical Record Numbers. Please note that prior to accessing these data elements, you should provide this letter of IRB approval to the applicable medical records personnel. Any changes to this Waiver of Authorization request must be approved by the IRB before the changes can take place. PROVISIONS: Unless otherwise noted, this approval relates to the research to be conducted under the above referenced title and/or to any associated materials considered by expedited review, e.g. study documents, etc. CHANGES: Should you choose to make any changes to the protocol that would involve the inclusion of human subjects or identified data from humans, please submit the change via MORTI to the Committee for the Protection of Human Subjects for review. Please note that prior to starting any experiments, it is your responsibility to give a copy of this document to all research personnel involved in the project and to discuss the project with each employee. Please ensure that only the most current IRB approved consent may be used during the study. Any changes to the protocol or consent must be approved by the IRB before the changes can take place. To post information on this clinical trial to the HMRI web site, the study must be listed on ClinicalTrials.gov. Please enter the ClinicalTrials.gov Identifier (i.e., the NCT number) and the Brief Summary from that listing for this trial by clicking on the Submit Web Info activity button in the left navigation list on the study page in the MORTI IRB Module. If you have any questions or comments, please contact the Office of Research Protection at 713-441-5848 or 713-441- 5837or come to MGJ3-014, 1130 John Freeman Blvd, Houston, TX 77030. The HMRI IRB is organized, operates, and is registered with the United States Office for Human Research Protections according to the regulations codified in the United States Code of Federal Regulations at 45 CFR 46 and 21 CFR 56. The HMRI IRB operates under the HMRI Federal Wide Assurance No. FWA00000438, as well as those of hospitals and institutions affiliated with the Institute. Animal subjects: All authors have confirmed that this study did not involve animal subjects or tissue. Conflicts of interest: In compliance with the ICMJE uniform disclosure form, all authors declare the following: Payment/services info: All authors have declared that no financial support was received from any organization for the submitted work. Financial relationships: All authors have declared that they have no financial relationships at present or within the previous three years with any organizations that might have an interest in the submitted work. Other relationships: All authors have declared that there are no other relationships or activities that could appear to have influenced the submitted work.

\section{References}

1. Kaiser MG, Haid RW, Subach BR, Barnes B, Rodts GE: Anterior cervical plating enhances arthrodesis after discectomy and fusion with cortical allograft. Neurosurgery. 2002, 50:229-238. 10.1097/00006123200202000-00001

2. Sen MK, Miclau T: Autologous iliac crest bone graft: should it still be the gold standard for treating nonunions?. Injury. 2007, 38:75-80. 10.1016/j.injury.2007.02.012

3. Grabowski G, Cornett CA: Bone graft and bone graft substitutes in spine surgery: current concepts and controversies. J Am Acad Orthop Surg. 2013, 21:51-60. 10.5435/JAAOS-21-01-51

4. Silber JS, Anderson DG, Daffner SD, et al.: Donor site morbidity after anterior iliac crest bone harvest for single-level anterior cervical discectomy and fusion. Spine. 2003, 28:134-139. 10.1097/00007632200301150-00008

5. Carter JD, Swearingen AB, Chaput CD, Rahm MD: Clinical and radiographic assessment of transforaminal lumbar interbody fusion using HEALOS collagen-hydroxyapatite sponge with autologous bone marrow aspirate. Spine J. 2009, 9:434-438. 10.1016/j.spinee.2008.11.004

6. Muschler GF, Nitto H, Matsukura Y, et al.: Spine fusion using cell matrix composites enriched in bone marrow-derived cells. Clin Orthop Relat Res. 2003, 407:102-118.

7. Hernigou P, Poignard A, Beaujean F, Rouard H: Percutaneous autologous bone-marrow grafting for nonunions. Influence of the number and concentration of progenitor cells. J Bone Joint Surg Am. 2005, 87:1430-1437. 10.2106/JBJS.D.02215

8. Khoueir P, Oh BC, Dirisio DJ, Wang MY: Multilevel anterior cervical fusion using a collagen-hydroxyapatite matrix with iliac crest bone marrow aspirate: an 18-month follow-up study. Neurosurgery. 2007, 61:963-970. 10.1227/01.neu.0000303192.64802.c6

9. Gan Y, Dai K, Zhang P, Tang T, Zhu Z, Lu J: The clinical use of enriched bone marrow stem cells combined with porous beta-tricalcium phosphate in posterior spinal fusion. Biomaterials. 2008, 29:3973-3982. 10.1016/j.biomaterials.2008.06.026

10. Papavero L, Zwonitzer R, Burkard I, Klose K, Herrmann HD: A composite bone graft substitute for anterior cervical fusion: assessment of osseointegration by quantitative computed tomography. Spine. 2002, 27:1037-1043. 10.1097/00007632-200205150-00008

11. Bae H, Kanim LEA, Spayde E, Wong P, Zhao L, Pradhan B, Delamarter R: Does autologous bone marrow aspirate enhance graft effectiveness for spinal fusion?. Semin Spine Surg. 2006, 18:2-11. 10.1053/j.semss.2006.01.002

12. Kalfas IH: Principles of bone healing. Neurosurg Focus. 2001, 10:1-4. 10.3171/foc.2001.10.4.2

13. Pan YH, Cheng CY, Chen SY, et al.: Complications of multilevel anterior cervical fusion . Tzu Chi Med J. 2004, 16:79-84.

14. Cho DY, Liau WR, Lee WY, Liu JT, Chiu CL, Sheu PC: Preliminary experience using a polyetheretherketone (PEEK) cage in the treatment of cervical disc disease. Neurosurgery. 2002, 51:1343-1349.

10.1227/01.NEU.0000035851.01555.22 
15. Burwell RG: The function of bone marrow in the incorporation of a bone graft . Clin Orthop Relat Res. 1985, 200:125-141.

16. Caplan AI: Mesenchymal stem cells: cell-based reconstructive therapy in orthopedics . Tissue Eng. 2005, 11:1198-1211. 10.1089/ten.2005.11.1198

17. Hartman EHM, Vehof JWM, Spauwen PHM, Jansen JA: Ectopic bone formation in rats: the importance of the carrier. Biomaterials. 2005, 26:1829-1835. 10.1016/j.biomaterials.2004.06.016

18. Shih HN, Shih LY, Sung TH, Chang YC: Restoration of bone defect and enhancement of bone ingrowth using partially demineralized bone matrix and marrow stromal cells. J Orthop Res. 2005, 23:1293-1299. 10.1016/j.orthres.2005.04.005

19. Muschler GF, Matsukura Y, Nitto H, et al.: Selective retention of bone marrow-derived cells to enhance spinal fusion. Clin Orthop Relat Res. 2005, 432:242-251.

20. van Gaalen SM, Dhert WJA, van den Muysenberg A, Oner FC, van Blitterswijk C, verbout AJ, De Bruijn JD: Bone tissue engineering for spine fusion: an experimental study on ectopic and orthotopic implants in rats . Tissue Eng. 2004, 10:231-239. 10.1089/107632704322791871

21. Cui Q, Ming Xiao Z, Balian G, Wang GJ: Comparison of lumbar spine fusion using mixed and cloned marrow cells. Spine. 2001, 26:2305-2310.

22. Tay BK, Le AX, Heilman M, Lotz J, Bradford DS: Use of a collagen-hydroxyapatite matrix in spinal fusion: a rabbit model. Spine. 1998, 23:2276-2281. 10.1097/00007632-199811010-00005

23. Bae HW, Zhao L, Kanim LEA, Wong P, Marshall D, Delamarter RB: Bone marrow enhances the performance of rhBMP-2 in spinal fusion: Rodent model. J Bone Joint Surg Am. 2013, 95:338-347.

24. Price CT, Connolly JF, Carantzas AC, Ilyas I: Comparison of bone grafts for posterior spinal fusion in adolescent idiopathic scoliosis. Spine. 2003, 28:793-798. 10.1097/01.BRS.0000058930.38079.24

25. Korovessis P, Koureas G, Zacharatos S, Papazisis Z, Lambiris E: Correlative radiological self-assessment and clinical analysis of evolution in instrumented dorsal and lateral fusion for degenerative lumbar spine disease. Autograft versus coralline hydroxyapatite. Eur Spine J. 2005, 14:630-638. 10.1007/s00586-0040855-5

26. Park DK, Rhee JM, Kim SS, Enyo Y, Yoshiok K: Do CT scans overestimate the fusion rate after anterior cervical discectomy and fusion?. J Spinal Disord Tech. 2015, 28:41-46. 10.1097/BSD.0b013e31829a37ac

27. Selby MD, Clark SR, Hall DJ, Freeman BJC: Radiologic assessment of spinal fusion . J Am Acad Orthop Surg. 2012, 20:694-703. 10.5435/JAAOS-20-11-694

28. Ploumis A, Mehbod A, Garvey T, Gilbert T, Transfeldt E, Wood K: Prospective assessment of cervical fusion status: plain radiographs versus CT-scan. Acta Orthop Belg. 2006, 72:342-346.

29. Ghiselli G, Wharton N, Hipp JA, Wong DA, Jatana S: Prospective analysis of imaging prediction of pseudarthrosis after anterior cervical discectomy and fusion: computed tomography versus flexionextension motion analysis with intraoperative correlation. Spine. 2011, 36:463-468. 10.1097/BRS.0b013e3181d7a81a

30. Taylor M, Hipp JA, Gertzbein SD, Gopinath S, Reitman CA: Observer agreement in assessing flexionextension X-rays of the cervical spine, with and without the use of quantitative measurements of intervertebral motion. Spine J. 2007, 7:654-658. 10.1016/j.spinee.2006.10.017 